\title{
How and When to Screen for Atrial Fibrillation after Stroke: Insights from Insertable Cardiac Monitoring Devices
}

\author{
Francesca Bridge, ${ }^{\mathrm{a}}$ Vincent Thijs ${ }^{\mathrm{a}, \mathrm{b}}$ \\ aDepartment of Neurology, Austin Health, Heidelberg, Victoria, Australia \\ ${ }^{b}$ Florey Institute of Neuroscience and Mental Health, Heidelberg, Victoria, Australia
}

The introduction of insertable cardiac monitoring devices has dramatically altered our understanding of the role of intermittent atrial fibrillation in cryptogenic stroke. In this narrative review we discuss the incidence, timing and relationship between atrial fibrillation and cryptogenic stroke, how to select patients for monitoring and the value and limitations of different monitoring strategies. We also discuss the role of empirical anticoagulation, and atrial fibrillation burden as a means of tailoring anticoagulation in patients at high risk of bleeding.

Keywords Stroke; Atrial fibrillation; Cryptogenic; Ischemia

\author{
Correspondence: Vincent Thijs \\ Florey Institute of Neuroscience and \\ Mental Health, Melbourne Brain Centre, \\ 245 Burgundy Street, Heidelberg, \\ Victoria 3084, Australia \\ Tel: +61-3-9035-3000 \\ Fax: +61-3-9458-5459 \\ Email:vincent.thijs@florey.edu.au \\ Received: February 29, 2016 \\ Revised: April 24, 2016 \\ Accepted: April 25, 2016 \\ The Florey Institute of Neuroscience and \\ Mental Health acknowledges the strong \\ support from the Victorian Government and \\ in particular the funding from the \\ Operational Infrastructure Support Grant.
}

\section{Introduction}

The prevention of stroke caused by atrial fibrillation (AF) is a major health priority. AF has been found to increase the risk of stroke by $3-5$ fold and strokes associated with AF have a poorer prognosis with increased rates of disability and mortality. ${ }^{12}$ Furthermore, survivors of strokes related to AF are at an increased risk of recurrent strokes. ${ }^{3}$

Paroxysmal AF (PAF) poses many clinical challenges due to its transient and often asymptomatic nature. As a result it is frequently a silent risk factor that may not be detected on routine investigations..$^{4-9}$ The prevalence and prognostic value of subclinical or occult AF is difficult to assess. Although traditionally PAF was thought to incur a similar risk of embolism as permanent $A F_{1}^{10,11}$ recent studies have shown a reduced risk of stroke with PAF. $^{12,13}$ Despite this apparent lower risk, treatment of PAF with anticoagulation is still warranted and the length of $A F$ is not currently used as a tool to select patients for anticoagulation. ${ }^{14}$

The detection of AF after ischemic stroke or transient ischemic attack (TIA) in any form is paramount, as it will strongly influence therapeutic decisions. Ischemic strokes occurring in the absence of AF (or other major cardiac sources) are best treated with antiplatelet medication; however, when AF is detected the treatment should be changed to anticoagulation. The commencement of anticoagulation following stroke in patients with AF has been found to be highly effective to prevent recurrent strokes. ${ }^{15,16}$

In this narrative review we canvas the topical and often controversial subject of PAF in cryptogenic stroke (CS). We will discuss the incidence, timing and relationship between $\mathrm{AF}$ and $\mathrm{CS}$, how to select patients for monitoring and the value and limitations of different monitoring strategies. We will also discuss the 
role of empirical anticoagulation, and AF burden as a means of tailoring anticoagulation in patients at high risk of bleeding.

\section{CS versus Embolic Stroke of Undetermined Source (ESUS)}

CS refers to ischemic strokes which lack a clearly determined mechanism. ${ }^{17}$ The reported incidence of CS varies considerably across studies from 20\%-40\% of all strokes. This wide variation can in part be explained by the lack of a generally accepted definition of CS. ${ }^{18}$ The TOAST (Trial of Org 10172 in Acute Stroke Treatment) classification identifies three situations where a patient may be deemed to have had a CS (or stroke of undetermined origin in TOAST terminology)..$^{19}$ Firstly, if the diagnostic assessment is incomplete, secondly if no cause is found despite extensive assessment and thirdly if no single cause can be isolated because there are multiple plausible causes of stroke identified. In this review we will focus on the second group of patients where no cause was found despite extensive assessment. Even within this group the term CS is not used in a standardized fashion, nor is the work up after stroke universally agreed upon. In order to circumvent these limitations, the concept of ESUS has been established to refer specifically to the subset of cases where the etiology of the stroke has been investigated following

Table 1. Cryptogenic stroke (CS) versus embolic stroke of undetermined source (ESUS)

\section{CS}

Diagnostic assessment incomplete; or

No cause found despite extensive assessment; or

Multiple potential causes, e.g., concurrent atrial fibrillation and relevant high grade stenosis of precerebral artery

\section{ESUS}

Stroke etiology remains unknown despite all of following investigations:

Brain imaging (CT/MRI)

Electrocardiogram

Transthoracic echocardiogram

24-hour Holter cardiac monitor

Imaging of extra and intra-cranial arteries a standardized pathway but the cause remains unknown. ${ }^{18}$ In order to be diagnosed with ESUS, patients must have undergone a series of investigations which include imaging of the brain (CT/ $\mathrm{MRI})$, an electrocardiogram, a transthoracic echocardiogram, a twenty-four hour Holter cardiac rhythm monitor and imaging of both the extra- and intra-cranial arteries supplying the area of brain ischemia. ESUS is diagnosed in patients with non-lacunar brain infarcts without intracranial or extracranial atherosclerosis (>50\% stenosis of the arteries supplying the area of ischemia) or a major-risk cardioembolic source and where no other specific cause of stroke is identified (Table 1). ${ }^{20}$

The majority of the current literature refers to $\mathrm{CS}$, however, this term is problematic as it is non-specific and does not label the reason why a cause of stroke was not identified or specify the work-up performed. ESUS is arguably a more useful and specific term when referring to patients who have undergone a work-up that has failed to reveal most common etiologies of stroke. The restricted definition of ESUS is also more useful in clinical trials.

These semantic differences aside, the risk of recurrent stroke after ESUS or CS is at least as high as other forms of ischemic stroke and appropriate secondary preventive measures are needed in this large population of patients. ${ }^{21}$

\section{Incidence of AF detection after CS}

There has been a wide variation of reported incidence AF following stroke ranging from $10 \%-30 \%$ of strokes. ${ }^{7,922-25}$ Some of this variation can be explained by the differences in study design, inclusion and exclusion criteria, differing monitoring strategies and the lack of consistency in follow-up duration. The highest incidence of AF has been identified using insertable cardiac monitoring (ICM) devices over an extended duration in patients with CS (Table 2). ${ }^{22,26,27}$

The EMBRACE trial, a large prospective trial, studied 572 patients with CS or TIA, aged $>55$ years and without a pre-existing diagnosis of AF. Patients were randomly assigned to undergo non-invasive ambulatory electrocardiography monitoring with

Table 2. Summary of studies/trials that investigated the incidence of atrial fibrillation detection following cryptogenic stroke

\begin{tabular}{|c|c|c|c|}
\hline Study & Sample size & Study design & Incidence of AF detection \\
\hline EMBRACE trial & $n=572$ & Randomized control study & $\begin{array}{l}\text { At } 90 \text { days: } 16.1 \% \text { of intervention group (non-invasive ambulatory } \\
\text { electrocardiogram monitoring) vs. } 3.2 \% \text { of control group }\end{array}$ \\
\hline CRYSTAL AF trial & $n=441$ & Randomized control study & $\begin{array}{l}\text { At } 6 \text { months: } 8.9 \% \text { of intervention group (insertible cardiac monitor } \\
\text { [ICM]) vs. } 1.4 \% \text { of control group } \\
12 \text { months: } 12.4 \% \text { of intervention group vs. } 2 \% \text { of control group } \\
36 \text { months: } 30 \% \text { of intervention group vs. } 3 \% \text { of control group }\end{array}$ \\
\hline Ziegler et al. (2015) & $n=1,247$ & Retrospective cohort analysis & $\begin{array}{l}30 \text { days: } 4.6 \% \text { of patients with ICM } \\
182 \text { days: } 12.2 \% \text { of patient with ICM }\end{array}$ \\
\hline
\end{tabular}


either a 30-day event triggered recorder (intervention group) or a conventional 24-hour monitor (control group). This study identified a detection rate of AF of $16.1 \%$ in the intervention group compared with $3.2 \%$ in the control group within 90 days of randomization (95\% confidence interval $[\mathrm{Cl}]$, 8.0-17.6; $P<0.001$ ). ${ }^{28}$

CRYptogenic Stroke And underlying AF (CRYSTAL AF) trial, a randomized control study which assessed whether long-term monitoring with an insertible cardiac monitor was more effective than conventional follow-up in patients with CS, found that by six months $8.9 \%$ of the patients in the ICM group compared to $1.4 \%$ in the control group had been diagnosed with $\mathrm{AF}^{22} \mathrm{CS}$ in the CRYSTAL AF trial was diagnosed differently than in EMBRACE: transesophageal echocardiography, intracranial vascular imaging and coagulation tests (in selected patients) were mandatory in addition to Holter/telemetry. By twelve months, the incidence of AF detection increased to $12.4 \%$ in the ICM group compared with $2 \%$ in the control group, and at 36 months, the rates of AF detection were $30 \%$ in the continuous monitoring arm versus $3 \%$ in the control group. ${ }^{22}$

One recent study examined a large $(n=1,247)$, real-world population of patients with ICMs inserted for detection of AF following loosely defined criteria $\mathrm{CS}^{29}$ This study found an increased rate of detection of AF compared with the CRYSTAL AF trial. Detection rate of AF was $4.6 \%$ and $12.2 \%$ at 30 and 182 days respectively. ${ }^{29}$ This represents a $37 \%$ relative increase in the rate of detection at 6 months compared with the CRYSTAL AF trial.

$A$ recent systematic review and meta-analysis suggest that $A F$ may be detected in up to $25 \%$ of TIA and stroke patients. ${ }^{25}$

\section{Timing of AF and stroke}

The temporal relationship between occult AF and stroke is controversial. ${ }^{30,31}$ The detection of AF on cardiac monitoring does not prove causality and while in the majority of situations it could represent the etiology of the stroke, alternative explanations and stroke mechanisms may occur. ${ }^{32}$ Occult AF may be an incidental finding in a population that shares many common risk factors with ischemic stroke. ${ }^{33}$ Alternatively, it has been postulated that AF may be the consequence of certain types of stroke. ${ }^{31}$ Strokes involving the insular cortex are at increased risk of generating neurogenic AF. Strokes in this region, which has a substantial role in the regulation of cardiac rate and rhythm, lead to changes in sympathovagal balance and may result in an arrhythmogenic effect. In such cases the risk of AF is significantly higher in the initial post-stroke period, however, may subside to a level of baseline population risk after a few weeks as the neurogenic autonomic and inflammatory mechanisms triggering AF dissipate. This finding has potential implications for treat- ment. This mechanism of AF is possibly transient, self-limiting and non-recurrent thus potentially may not necessitate life-long anticoagulation. In practice, however this potential mechanism is difficult to prove and currently there is no evidence that patients with new onset $A F$ in the context of insular infarction should be treated differently.

Evidence to support a temporal link between $\mathrm{AF}$ and ischemic stroke has been questioned in smaller studies ${ }^{34,35}$ Recently, however, a larger cohort study in patients with implantable devices found a strong association between AF burden of $>5.5$ hours and short term risk of ischemic stroke (odds ratio $4.21 ; 95 \% \mathrm{Cl}$, 1.53-3.44). ${ }^{30}$ The risk was highest in the initial 5-10 days following the episode of AF and by 30 days following the event was no longer elevated. The finding of a marked but short-term increased risk of stroke may provide evidence for targeted intermittent anticoagulation using rapidly acting anticoagulants, exclusively during the high-risk period for stroke prevention. ${ }^{36}$ Trials are planned to compare intermittent, monitoring based "on demand" anticoagulation versus chronic anticoagulation, especially in patients with a low burden of AF.

\section{Threshold of AF burden}

There is no general agreement or consistent data to determine the relationship between the duration of AF detected on monitoring and the stroke risk, with different studies quoting different thresholds of AF required to increase risk. In a non-stroke population the TRENDS study found that a burden of greater than 5.5 hours on any given day during the preceding 30 days conferred double the risk of thromboembolism. ${ }^{11}$ Low atrial tachycardia/AF burden ( $<5.5$ hours on each preceding day) resulted in a thromboembolism risk similar to not having AF/atrial tachycardia. However, other studies have quoted a much lower burden to increase stroke risk. The SURPRISE study found that 1-4 hours increased risk and the MOST study identified that atrial tachyarrhythmia of more than five minutes at least doubled the incidence of stroke or death. ${ }^{37,38}$

\section{Identifying patients at risk of AF after CS or TIA}

Identifying a key patient population that would be likely to benefit from long-term cardiac monitoring is important so as to increase the yield of the investigation and ensure cost-effectiveness. However, within the literature there remains considerable contention regarding which risk factors are clinically useful. A number of proposed risk factors have been considered including clinical features, electrocardiographic parameters, echocardio- 
graphic abnormalities and radiographic evidence.

A number of clinical features that may represent independent risk factors for a new diagnosis of AF after TIA or stroke have been studied. These include age, diabetes mellitus, arterial hypertension, dyslipidemia, smoking, $\mathrm{CHADS}_{2}$ score and $\mathrm{CHA}_{2} \mathrm{DS}_{2}-$ VASc score.

Advanced age has been consistently identified as an independent risk factor for AF post CS and this finding has been presented in a number of different studies. ${ }^{6,2,39,40} \mathrm{~A}$ recent study investigated predictors of $\mathrm{AF}$ in $\mathrm{CS}$ or TIA in 221 patients who received an ICM. This study evaluated a number of demographic and clinical features and found that increased age was the only clinical feature that was independently associated with increased incidence of AF during follow-up. ${ }^{40}$ This finding was supported by other studies. ${ }^{24,39}$

While $\mathrm{CHADS}_{2} / \mathrm{CHA}_{2} \mathrm{DS}_{2}$-VASc score has been found to increase the risk of $\mathrm{AF}_{1}{ }^{41}$ this parameter has not been recognized as a significant risk factor in the post-CS setting. ${ }^{24,40}$ This may be due to sample size issues or the high prevalence of elevated $\mathrm{CHADS}_{2} / \mathrm{CHA}_{2} \mathrm{DS}_{2}$-VASc score in this secondary prevention population.

Electrocardiographic findings could be a simple and effective method for selecting patients who should undergo further monitoring. There is growing evidence for the importance of atrial premature contractions. ${ }^{5,28,42} \mathrm{~A}$ recent prospective cohort subanalysis of the EMBRACE study found that the number of atrial premature beats on a routine 24-hour Holter electrocardiogram was a strong dose-dependent predictor of prevalent subclinical $\mathrm{AF}^{28}$ The detection rate incrementally increased from $<9 \%$ in patients with $<100$ atrial premature beats per 24 hours, to $40 \%$ among patients with 1,500 atrial premature beats. ${ }^{28} \mathrm{~A}$ prolonged $P R$ interval on electrocardiogram was independently associated with increased risk of detecting $\mathrm{AF}$ in $\mathrm{CS}$ or TIA. ${ }^{40}$

Echocardiographic parameters have been explored for their role in increasing the likelihood of AF following $\mathrm{CS}^{43,44}$ Interestingly, compared to patients with a left atrium within the normal limits, moderate to severe left atrial enlargement increased the risk of recurrent cryptogenic or cardioembolic stroke, however, no interaction has been found between left atrial enlargement and $\mathrm{AF}^{44}{ }^{44}$ This study suggests that the effect of left atrial enlargement on recurrent $\mathrm{CS}$ and cardioembolic stroke may be mediated by a mechanism independent of $\mathrm{AF}^{44}$ Unfortunately, no continuous cardiac monitoring was performed in this study to conclusively prove this contention. In addition to size, left atrial morphology has been evaluated. A single lobed left atrial appendage predominated in CS patients..$^{45}$ Morphologic features of the left atrial appendage may predispose or protect against embolism in patients with established $\mathrm{AF}^{46}$ Four types of left atrial morphology have been identified: cactus, chicken wing, windstock and cauliflower. Different left atrial appendage morphologies have been correlated with a different risk of stroke or TIA, however, there have been conflicting results as to which morphology confers the most significant stroke risk. Di Biase et al.. ${ }^{46}$ in a retrospective study found that while the chicken wing was the most prevalent morphology, it was least associated with stroke or TIA. The risk of previous stroke or TIA was similar across all other morphologies. In contrast, a prospective study performed by Korhonen et al found a significantly increased prevalence of the "chicken wing" morphology in the stroke subgroup compared with the control group. ${ }^{45}$ The marked discrepancy between these studies may in part be explained by different classification criteria's and overlap between some morphological classes.

Particular radiographic features identified on CT or MRI have been identified as significant for predicting a likely cardioembolic source of stroke. These patterns include multiple areas of acute infarcts, infarcts involving multiple vascular territories and multiple chronic infarcts. However, these radiographic changes have not been consistently identified in the post-CS setting and may be more in keeping with established AF as opposed to occult AF. A retrospective analysis of the brain imaging of 212 patients with CS in the ICM arm of the CRYSTAL AF trial found no clear topographical pattern of acute infarction significantly associated with AF detection after $\mathrm{CS}^{47}$ However, other features such as the identification of coexisting chronic and acute infarcts or leukoaraiosis were found to have a 2-3 times higher rate of $\mathrm{AF}^{47}$ The finding that prior infarction seen on neuroimaging is independently associated with AF is supported by Favilla et al. ${ }^{24}$

Finally, biochemical markers such as natriuretic peptides are increased in AF and cardioembolic strokes. ${ }^{48,49}$ Pro-B-type natriuretic peptide levels may be highly predictive of incident $A F$ in patients in sinus rhythm and after $\mathrm{CS}^{49,50}$

Despite significant advances, at present, the decision to strongly pursue AF after TIA or ischemic stroke remains a clinical decision guided by stroke neurologists as to which patients are at increased risk of AF and should undergo further monitoring. No single feature is able to conclusively disprove the presence of AF. Of course, the decision to continue monitoring also depends on the treatment implication of finding AF. It is agreed to investigate only CS patients where the risk-benefit balance would favor the initiation of anticoagulation if AF would be identified. ${ }^{7,33}$

\section{Monitoring strategies to identify AF after CS or TIA}

Having selected appropriate patients for further monitoring of $\mathrm{AF}$ after $\mathrm{CS}$, there is currently no uniform consensus on which 
modality to use. ${ }^{8} \mathrm{~A}$ variety of techniques have been utilized including in-hospital monitoring, serial electrocardiographs, Holter monitors, external event or loop recorders ${ }^{22}$ and more long-term modalities such as cardiac event monitors, recordings from pacemakers or implantable cardiac defibrillations, patient-triggered daily electrocardiographs and mobile cardiac outpatient telemetry..$^{24}$

External monitoring modalities (for example intermittent hand-held electrocardiogram recordings or long term Holters/ mobile cardiac outpatient telemetry) are reliant on patient compliance. ${ }^{6,51}$ Compliance declines if monitoring is prolonged. A systematic review and meta-analysis of three randomized controlled trials and 13 observational studies revealed a significantly higher AF detection with implantable loop recorder devices compared to wearable devices. ${ }^{52}$

Accepting continuous monitoring strategy as the "gold" standard detection method, it is now possible to compare currently available intermittent techniques and determine its sensitivity with the gold standard using simulation technique. Compared to continuous rhythm monitoring in 168 ICM patients of the CRYSTAL AF trial, such a simulation study found that long-term continuous electrocardiographic monitoring with ICMs was significantly more effective than with any of the simulated intermittent monitoring strategies. For instance the sensitivity of a 30day event recorder for AF was only $22.8 \%{ }^{26}$ The rates of AF may have been lower in CRYSTAL AF because it was performed in a clinical trial population and patients were studied relatively late after the stroke.

The current guideline for patients who have experienced an acute CS or TIA is for prolonged rhythm monitoring for 30 days within six months of the index event with a low degree of evidence rating. ${ }^{23} \mathrm{~A}$ monitoring period of 30 days may not be optimal as in CRYSTAL AF more than half of the AF episodes were detected after the initial month of monitoring. ${ }^{22}$ As such important opportunities for secondary stroke prevention with the introduction of anticoagulation may be missed if monitoring is not prolonged. $^{8}$

Whilst implantable loop recorders are likely to be the most reliable method of screening for occult AF, these devices are slightly invasive and expensive and thus should be used in a select patient population according to the patients risk profile. ${ }^{53,54}$

\section{Empirical anticoagulation}

In light of the inherent difficulties with diagnosing occult AF and the significant opportunity for secondary stroke prevention, empirical anticoagulation in patients with CS has been considered. ${ }^{20,55}$ However, the trends towards reduction in ischemic stroke are offset by increases in major intra- and extra-cranial hemorrhages, especially with vitamin $\mathrm{K}$ antagonists. While novel oral anticoagulants carry a decreased risk of bleeding compared with warfarin, approaching the risk of aspirin, the treatment effect with the novel oral anticoagulants in patients with sinus rhythm remains unknown. ${ }^{56}$ Furthermore, anticoagulation has not been proven to be superior to antiplatelet therapy in patients without AF. Three major trials are currently investigating a strategy of novel oral anticoagulants versus aspirin in patients with ESUS.

\section{Targeted anticoagulation in patients at high risk of bleeding}

In patients who are at a significantly increased risk of bleeding, for example patients with high HAS-BLED scores, patients receiving concurrent antiplatelet therapy or those with end stage renal disease, long term anticoagulation may not be safe. With new technologies such as ICM devices, it is possible to monitor for AF burden and make a more accurate and individualized riskbenefit assessment. An option for minimization of anticoagulant risk could be the transient use of oral anticoagulation linked to onset and offset of an episode of AF in patients at high risk of bleeding and low burden of AF. One such study used data from real-world practice setting in patients with $\mathrm{AF}$ and ICM devices. ${ }^{57}$ Up to $87 \%$ of patients had a low AF burden, classified as presence of $A F$ in $<1 \%$ of the time and were therefore eligible to discontinue anticoagulation. During follow-up, no strokes were observed and bleeding occurred only in patients who remained on anticoagulation. This small study provides some initial evidence to support the safe cessation of oral anticoagulation in patients who are at increased risk of bleeding and are being continuously and objectively monitored for AF.

\section{Conclusion}

The ability to detect and monitor the presence of AF accurately after TIA and stroke has changed our understanding of the mechanisms underlying CS. These devices will have an impact in the years to come on how the secondary prevention of stroke can be optimized.

\section{References}

1. Wolf PA, Abbott RD, Kannel WB. Atrial fibrillation as an independent risk factor for stroke: the Framingham Study. Stroke 1991;22:983-988.

2. Thijs V. More bad news about atrial fibrillation. Eur Heart J 
2004;25:1670-1671.

3. Lin HJ, Wolf PA, Kelly-Hayes M, Beiser AS, Kase CS, Benjamin EJ, et al. Stroke severity in atrial fibrillation The Framingham Study. Stroke 1996;27:1760-1764.

4. Sinha AM, Diener HC, Morillo CA, Sanna T, Bernstein RA, Di Lazzaro V, et al. Cryptogenic Stroke and underlying Atrial Fibrillation (CRYSTAL AF): design and rationale. Am Heart J 2010; 160:36-41.e1.

5. Pinho J, Braga CG, Rocha S, Santos AF, Gomes A, Cabreiro A, et al. Atrial ectopic activity in cryptogenic ischemic stroke and TIA: a risk factor for recurrence. J Stroke Cerebrovasc Dis 2015; 24:507-510.

6. Grond $M$, Jauss $M$, Hamann $G$, Stark $E$, Veltkamp $R$, Nabavi $D$, et al. Improved detection of silent atrial fibrillation using 72hour Holter ECG in patients with ischemic stroke: a prospective multicenter cohort study. Stroke 2013;44:3357-3364.

7. Gladstone DJ, Spring M, Dorian P, Panzov V, Thorpe KE, Hall J, et al. Atrial fibrillation in patients with cryptogenic stroke. $N$ Engl J Med 2014;370:2467-2477.

8. Sposato LA, Klein FR, Jáuregui $A$, Ferrúa $M$, Klin P, Zamora $R$, et al. Newly diagnosed atrial fibrillation after acute ischemic stroke and transient ischemic attack: importance of immediate and prolonged continuous cardiac monitoring. J Stroke Cerebrovasc Dis 2012;21:210-216.

9. Healey JS, Connolly SJ, Gold MR, Israel CW, Van Gelder IC, Capucci $A$, et al. Subclinical atrial fibrillation and the risk of stroke. N Engl J Med 2012;366:120-129.

10. Turakhia MP, Ullal AJ, Hoang DD, Than CT, Miller JD, Friday KJ, et al. Feasibility of extended ambulatory electrocardiogram monitoring to identify silent atrial fibrillation in high-risk patients: the Screening Study for Undiagnosed Atrial Fibrillation (STUDY-AF). Clin Cardiol 2015;38:285-292.

11. Glotzer TV, Daoud EG, Wyse DG, Singer DE, Ezekowitz MD, Hilker $C_{\text {, et }}$ al. The relationship between daily atrial tachyarrhythmia burden from implantable device diagnostics and stroke risk: the TRENDS study. Circ Arrhythm Electrophysiol 2009:2:474-480.

12. Vanassche T, Lauw MN, Eikelboom JW, Healey JS, Hart RG, Alings $M$, et al. Risk of ischaemic stroke according to pattern of atrial fibrillation: analysis of 6563 aspirin-treated patients in ACTIVE-A and AVERROES. Eur Heart J 2015:36:281-287a.

13. Hohnloser SH, Shestakovska O, Eikelboom J, Franzosi MG, Tan $\mathrm{RS}$, Zhu J, et al. The effects of apixaban on hospitalizations in patients with different types of atrial fibrillation: insights from the AVERROES trial. Eur Heart J 2013;34:2752-2759.

14. Camm AJ, Lip GY, De Caterina R, Savelieva I, Atar D, Hohnloser SH, et al. 2012 focused update of the ESC Guidelines for the management of atrial fibrillation: an update of the 2010 ESC
Guidelines for the management of atrial fibrillation. Developed with the special contribution of the European Heart Rhythm Association. Eur Heart J 2012:33:2719-2747.

15. EAFT (European Atrial Fibrillation Trial) Study Group. Secondary prevention in non-rheumatic atrial fibrillation after transient ischaemic attack or minor stroke. Lancet 1993;342: 1255-1262.

16. Ntaios G, Papavasileiou V, Diener HC, Makaritsis K, Michel P. Nonvitamin-K-antagonist oral anticoagulants in patients with atrial fibrillation and previous stroke or transient ischemic attack: a systematic review and meta-analysis of randomized controlled trials. Stroke 2012;43:3298-3304.

17. Mohr JP. Cryptogenic stroke. N Engl J Med 1988;318:11971198.

18. Hart RG, Diener HC, Coutts SB, Easton JD, Granger CB, O'Donnell MJ, et al. Embolic strokes of undetermined source: the case for a new clinical construct. Lancet Neurol 2014;13: 429-438.

19. Adams HP Jr, Bendixen BH, Kappelle U, Biller J, Love BB, Gordon $D L$, et al. Classification of subtype of acute ischemic stroke. Definitions for use in a multicenter clinical trial. TOAST. Trial of Org 10172 in Acute Stroke Treatment. Stroke 1993;24: 35-41.

20. Hart RG, Diener HC, Connolly SJ. Embolic strokes of undetermined source: support for a new clinical construct--authors' reply. Lancet Neurol 2014;13:967.

21. Li L, Yiin GS, Geraghty OC, Schulz UG, Kuker W, Mehta Z, et al. Incidence, outcome, risk factors, and long-term prognosis of cryptogenic transient ischaemic attack and ischaemic stroke: a population-based study. Lancet Neurol 2015;14:903-913.

22. Sanna T, Diener HC, Passman RS, Di Lazzaro V, Bernstein RA, Morillo $C A$, et al. Cryptogenic stroke and underlying atrial fibrillation. N Engl J Med 2014;370:2478-2486.

23. Kernan WN, Ovbiagele B, Black HR, Bravata DM, Chimowitz MI, Ezekowitz MD, et al. Guidelines for the prevention of stroke in patients with stroke and transient ischemic attack: a guideline for healthcare professionals from the American Heart Association/American Stroke Association. Stroke 2014; 45:2160-2236.

24. Favilla CG, Ingala $E_{1}$ Jara J, Fessler $E_{1}$ Cucchiara $B$, Messé $S R$, et al. Predictors of finding occult atrial fibrillation after cryptogenic stroke. Stroke 2015;46:1210-1215.

25. Sposato LA, Cipriano LE, Saposnik G, Ruíz Vargas E, Riccio PM, Hachinski V. Diagnosis of atrial fibrillation after stroke and transient ischaemic attack: a systematic review and metaanalysis. Lancet Neurol 2015;14:377-387.

26. Choe WC, Passman RS, Brachmann J, Morillo CA, Sanna T, Bernstein $\mathrm{RA}$, et al. A comparison of atrial fibrillation monitoring 
strategies after cryptogenic stroke (from the Cryptogenic Stroke and Underlying AF Trial). Am J Cardiol 2015;116:889893.

27. Cotter PE, Martin PJ, Ring L, Warburton EA, Belham M, Pugh PJ. Incidence of atrial fibrillation detected by implantable loop recorders in unexplained stroke. Neurology 2013;80:15461550.

28. Gladstone DJ, Dorian $P$, Spring $M$, Panzov V, Mamdani M, Healey JS, et al. Atrial premature beats predict atrial fibrillation in cryptogenic stroke: results from the EMBRACE trial. Stroke 2015;46:936-941.

29. Ziegler PD, Rogers JD, Ferreira SW, Nichols AJ, Sarkar S,

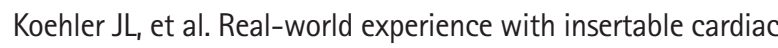
monitors to find atrial fibrillation in cryptogenic stroke. Cerebrovasc Dis 2015;40:175-181.

30. Turakhia MP, Ziegler PD, Schmitt SK, Chang Y, Fan J, Than CT, et al. Atrial fibrillation burden and short-term risk of stroke: case-crossover analysis of continuously recorded heart rhythm from cardiac electronic implanted devices. Circ Arrhythm Electrophysiol 2015;8:1040-1047.

31. Sposato LA, Riccio PM, Hachinski V. Poststroke atrial fibrillation: cause or consequence? Critical review of current views. Neurology 2014;82:1180-1186.

32. Hart R, Pearce L, Miller V, Anderson D, Rothrock J, Albers G, et al. Cardioembolic vs. noncardioembolic strokes in atrial fibrillation: frequency and effect of antithrombotic agents in the stroke prevention in atrial fibrillation studies. Cerebrovasc Dis 2000;10:39-43.

33. Akrawinthawong $K$, Venkatesh Prasad $K$, Mehdirad AA, Ferreira SW. Atrial fibrillation monitoring in cryptogenic stroke: the gaps between evidence and practice. Curr Cardiol Rep 2015; 17:118.

34. Brambatti M, Connolly SJ, Gold MR, Morillo CA, Capucci A,

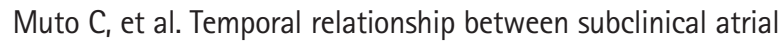
fibrillation and embolic events. Circulation 2014;129:20942099.

35. Daoud EG, Glotzer TV, Wyse DG, Ezekowitz MD, Hilker C, Koehler J, et al. Temporal relationship of atrial tachyarrhythmias, cerebrovascular events, and systemic emboli based on stored device data: a subgroup analysis of TRENDS. Heart Rhythm 2011;8:1416-1423.

36. Passman R, Leong-Sit P, Andrei AC, Huskin A, Tomson T, Bernstein $R$, et al. Targeted anticoagulation for atrial fibrillation guided by continuous rhythm assessment with an insertable cardiac monitor: the Rhythm Evaluation for Anticoagulation with Continuous Monitoring (REACT.COM) pilot study. J Cardiovasc Electrophysio/ 2016;27:264-270.

37. Christensen LM, Krieger DW, Højberg S, Pedersen OD, Karlsen
FM, Jacobsen MD, et al. Paroxysmal atrial fibrillation occurs often in cryptogenic ischaemic stroke. Final results from the SURPRISE study. Eur J Neurol 2014;21:884-889.

38. Glotzer TV, Hellkamp AS, Zimmerman J, Sweeney MO, Yee R, Marinchak $R$, et al. Atrial high rate episodes detected by pacemaker diagnostics predict death and stroke: report of the Atrial Diagnostics Ancillary Study of the MOde Selection Trial (MOST). Circulation 2003;107:1614-1619.

39. Lazzaro MA, Krishnan K, Prabhakaran S. Detection of atrial fibrillation with concurrent holter monitoring and continuous cardiac telemetry following ischemic stroke and transient ischemic attack. J Stroke Cerebrovasc Dis 2012;21:89-93.

40. Thijs VN, Brachmann J, Morillo CA, Passman RS, Sanna T, Bernstein RA, et al. Predictors for atrial fibrillation detection after cryptogenic stroke: results from CRYSTAL AF. Neurology 2016; 86:261-269.

41. Tischer $T$, Schneider R, Lauschke J, Nesselmann C, Klemm A, Diedrich $D$, et al. Prevalence of atrial fibrillation in patients with high CHADS2- and CHA2DS2VASc-scores: anticoagulate or monitor high-risk patients? Pacing Clin Electrophysio/ 2014; 37:1651-1657.

42. Gaillard N, Deltour S, Vilotijevic B, Hornych A, Crozier S, Leger $A$, et al. Detection of paroxysmal atrial fibrillation with transtelephonic EKG in TIA or stroke patients. Neurology 2010;74: 1666-1670.

43. Psaty BM, Manolio TA, Kuller LH, Kronmal RA, Cushman $M$, Fried $L P$, et al. Incidence of and risk factors for atrial fibrillation in older adults. Circulation 1997;96:2455-2461.

44. Yaghi S, Moon YP, Mora-McLaughlin C, Willey JZ, Cheung K, Di Tullio $M R$, et al. Left atrial enlargement and stroke recurrence: the Northern Manhattan Stroke Study. Stroke 2015;46: 1488-1493.

45. Korhonen M, Muuronen A, Arponen O, Mustonen $P$, Hedman $M_{1}$ Jäkälä $P$, et al. Left atrial appendage morphology in patients with suspected cardiogenic stroke without known atrial fibrillation. PloS One 2015;10:e0118822.

46. Di Biase L, Santangeli P, Anselmino M, Mohanty P, Salvetti I, Gili $S$, et al. Does the left atrial appendage morphology correlate with the risk of stroke in patients with atrial fibrillation? Results from a multicenter study. J Am Coll Cardiol 2012;60: 531-538.

47. Bernstein RA, Di Lazzaro V, Rymer MM, Passman RS, Brachmann J, Morillo CA, et al. Infarct topography and detection of atrial fibrillation in cryptogenic stroke: results from CRYSTAL AF. Cerebrovasc Dis 2015;40:91-96.

48. Llombart V, Antolin-Fontes A, Bustamante A, Giralt D, Rost NS, Furie $K_{1}$ et al. B-type natriuretic peptides help in cardioembolic stroke diagnosis: pooled data meta-analysis. Stroke 2015;46: 
1187-1195.

49. Patton KK, Ellinor PT, Heckbert SR, Christenson RH, DeFilippi C, Gottdiener JS, et al. N-terminal pro-B-type natriuretic peptide is a major predictor of the development of atrial fibrillation: the Cardiovascular Health Study. Circulation 2009;120:17681774.

50. Fonseca AC, Brito D, Pinho e Melo T, Geraldes R, Canhão P, Caplan $L R$, et al. N-terminal pro-brain natriuretic peptide shows diagnostic accuracy for detecting atrial fibrillation in cryptogenic stroke patients. Int J Stroke 2014;9:419-425.

51. Ziegler PD, Glotzer TV, Daoud EG, Wyse DG, Singer DE, Ezekowitz MD, et al. Incidence of newly detected atrial arrhythmias via implantable devices in patients with a history of thromboembolic events. Stroke 2010;41:256-260.

52. Afzal MR, Gunda S, Waheed S, Sehar N, Maybrook RJ, Dawn B, et al. Role of outpatient cardiac rhythm monitoring in cryptogenic stroke: a systematic review and meta-analysis. Pacing Clin Electrophysiol 2015;38:1236-1245.
53. Levin L̊, Husberg M, Sobocinski PD, Kull VF, Friberg L, Rosenqvist $M$, et al. A cost-effectiveness analysis of screening for silent atrial fibrillation after ischaemic stroke. Europace 2015; 17:207-214.

54. Abdul-Rahim AH, Lees KR. Screening for atrial fibrillation after stroke or TIA. Lancet Neurol 2015;14:345-347.

55. Sacco RL, Prabhakaran S, Thompson J, Murphy A, Sciacca RR, Levin $B$, et al. Comparison of warfarin versus aspirin for the prevention of recurrent stroke or death: subgroup analyses from the Warfarin-Aspirin Recurrent Stroke Study. Cerebrovasc Dis 2006;22:4-12.

56. Connolly SJ, Eikelboom J, Joyner C, Diener HC, Hart R, Golitsyn $\mathrm{S}$, et al. Apixaban in patients with atrial fibrillation. $N$ Engl $J$ Med 2011;364:806-817.

57. Mascarenhas DA, Farooq MU, Ziegler PD, Kantharia BK. Role of insertable cardiac monitors in anticoagulation therapy in patients with atrial fibrillation at high risk of bleeding. Europace 2015;pii:euv350. 